\title{
Determine the Level of Organizational Learning Capability in Teaching Hospitals in Bandar Abbas City-Iran
}

\author{
Fereshteh Farzianpour $^{1 *}$, Afife Irani ${ }^{1}$, Abbas Rahimi Foroushani² \\ ${ }^{1}$ Department of Health Management and Economics, School of Public Health, Tehran University of Medical \\ Sciences, Tehran, Iran \\ ${ }^{2}$ Department of Epidemiology and Biostatistics, School of Public Health, Tehran University of Medical Sciences, \\ Tehran, Iran \\ Email: "farzianp@sina.tums.ac.ir, a.irani5@yahoo.com,rahimifo@tums.ac.ir
}

Received 9 September 2015; accepted 9 January 2016; published 12 January 2016

Copyright (C) 2016 by authors and Scientific Research Publishing Inc.

This work is licensed under the Creative Commons Attribution International License (CC BY). http://creativecommons.org/licenses/by/4.0/

c) (i) Open Access

\section{Abstract}

Background: The hospital is a scientific organization that despite much progress, today, is also dependent on manpower. One of the main requirements for the proper functioning of manpower is that through learning, they be updated in terms of knowledge. Thus, the aim of this study was to determine the level of Organizational Learning Capability in hospitals in Bandar Abbas City-Iran. Methods: In 2014, this descriptive-analytic study was conducted in hospitals in Bandar Abbas City. The data was collected through the Gomez questionnaire for organizational learning from $290 \mathrm{em}$ ployees of hospitals. Data analysis was done using software SPSS V.20 and by the Mann-Whitney U test and the Kruskal-Wallis test. Results: Organizational Learning Capability in governmental, private and social security hospitals were $0.31 \pm 53.06,9.38 \pm 47.38$ and $0.27 \pm 50.74$, respectively. The results of the Kruskal-Wallis test showed that the relationship between the variables of employment status $(p=0.034)$, occupational categories $(p=0.043)$, and type of ownership $(p=0.02)$, was significant with the organizational learning capability but such a significant relationship was not observed in terms of age, educational level and employment status. The results of the MannWhitney $U$-test indicated a significant association between marital status $(p=0.029)$ and type of hospital $(p=0.049)$ with the organizational learning capability. Conclusion: Need to up-to-dating of staff's knowledge has made undeniable the role of organizational learning. According to the results, managers have to provide conditions for improving the status quo through promoting organizational learning and extend the ability of the organization for growth and progress.

\footnotetext{
*Corresponding author.
}

How to cite this paper: Farzianpour, F., Irani, A. and Foroushani, A.R. (2016) Determine the level of Organizational Learning Capability in Teaching hospitals in Bandar Abbas City-Iran. Health, 8, 24-31. 


\section{Keywords}

\section{Organizational Learning Capability, Hospital, Bandar Abbas}

\section{Background}

In recent years, changes in science and technology occur much faster than before. Development of science and technology changed all boundaries of human activity like the organization and its activities. Today, organizations are looking for practical solutions to control and profit from this flow. In this context, learning in organization medium to fit the organization capabilities and human resource to its needs, has become an important issue that deserves attention. This affair promoted the position of learning's in the organization to a critical factor for growth and innovation [1]-[3] and the organization's effectiveness and growth have become significantly dependent on the learning capacity of the organization [2] [4].

On the other hand, the level of paying attention to growth and innovation is of facilitators of learning in organizations [4]-[7]. The existence of such a relationship between organizations growth and the learning capability caused that organizations increasingly emphasize on enhancing organizational learning and creating learning organizations [8].

Organizational learning capability is a set of managerial and organizational factors that facilitate the learning process and help the organization and its members in order to update their knowledge [6] [7]. The managerial and organizational factors listed in the definition, include management commitment, systemic vision, outdoor space and experimentation and the transferring and integration of knowledge, which totally form the four domains of organizational learning capabilities.

Management commitment indicates the importance of learning for management and provides the main requirements in this field and the systemic vision refers to the organization cognition as a whole which is composed of interrelated components. Outdoor space and experimentation refer the personnel liberty in the use of knowledge and new methods in the organization and finally transferring and integration refers to the free flow of information in the organization which prepares the possibility of integration and transforming it into a coherent and universal knowledge [4].

Learning capability is an important factor for organizations for growth and innovation [5] and a set of tangible and intangible resources or skills which is used by the organization to achieve competitive advantage [9]. The organizational learning capability also demonstrates the capacity to effectively create and extend ideas in dealing with diverse organizational boundaries through innovation and intensive management practices [10]. Ulrich knows organizational learning capability as managers' capacity within an organization for production and expansion of important and effective ideas [11].

Organizational learning is associated with many positive outcomes such as job satisfaction, patient satisfaction and the capability to adopt and deal with changes and challenges and enhancing the professional competence of the staff [12] and also promotes internal marketing and organizational commitment of employees [13]. Moreover, in several aspects, the hospital environment is different from the other workplaces. Hospital is an academic environment and the knowledge related to medical sciences is in progress and changes day-to-day. Also, despite massive technological advances, the hospital is one of the organizations that is highly dependent on human labor. Another difference of the hospital with other organizations is due to its being as a service provider and the specific requirements of its customers. Specific mental and emotional conditions of patients necessitate the existence of motivated personnel in the hospital [14] [15]. Based on the foregoing, scientific being and need to the modern science make the discussion of organizational learning in hospitals inevitable. Therefore, the aim of this study is to investigate the organizational learning capabilities of the staff in the hospitals of Bandar Abbas City.

\section{Methods}

\subsection{Study Design and Data Collection}

This study was a descriptive-analytic research that was carried out in 2014. The research environment has been consisted the hospitals in Bandar Abbas City (3 public hospitals, 2 private hospitals, and 1 Social Security hospital) 
and all the hospital staff formed the study population. The 290 employees were selected through the sampling formula and with confidence coefficient of $95 \%$.

$$
\begin{aligned}
& n=\frac{z 1-\left(\frac{a}{2}\right)^{2} \times \sigma^{2}}{d^{2}}=\frac{1.96^{2} \times 11.3^{2}}{2^{2}}=123 \\
& N=123 \times 2=246 \\
& N=\frac{246}{85 \%} \\
& =289=290
\end{aligned}
$$

The Gomez questionnaire was used to assess the organizational learning capability variable [4]. The questionnaire consists of 17 items in four dimensions of management commitment, systemic vision, outdoor space and experimentation and transferring and integration of knowledge that measures the organizational learning capability by the 5-responce Likert scale (totally disagree, disagree, no idea, agree, and strongly agree) [appendix].

The reliability of the questionnaire was confirmed using the Cronbach's alpha (82.4 \%). After completing the questionnaire by staff, the collected data were analyzed by the SPSS V.20 Software. The Kolmogorov-Smirnov test results indicated the non-normality of the research variables, therefore, the nonparametric Mann-Whitney U test and the Kruskal-Wallis test were applied to investigate the relation between learning capabilities and demographic variables, type of hospital activity (general or specialty) and hospital ownership (public, private and Social Security).

\subsection{Ethical Considerations}

This study received approval from the ethics committee of Tehran University of Medical Sciences (TUMS). All participants gave their oral consents for interview. We kept the information of the participants confidential.

\section{Results}

Among 290 samples employees in the study, 226 (77.9\%) were female and 22.1\% were male. Most people were in the age group 31 to 40 years (131 people-45.2\%) and 20 to 30 years (112 people-38.6\%). 223 people (76.9\%) were married and others (67 people-23.1\%) were single. 55.9\% of employees had a bachelor's degree and for each degree of diploma (51 people), Associate's (54 people) and MS-up, 23 people existed. Finally, the frequency of people in the groups separated by work experience for groups of 1 to 10 years, 11 to 20 years and 21 and 30 years were 166, 93 and 31 people, respectively (Table 1).

In Table 2, the organizational learning capability in the studied hospitals is presented according to the three

\begin{tabular}{|c|c|c|c|c|c|}
\hline & Variable & Frequency \% & & able & Frequency \% \\
\hline \multirow{3}{*}{ Gender } & Man & $64(22.1)$ & \multirow{4}{*}{$\begin{array}{c}\text { Educational } \\
\text { level }\end{array}$} & Diploma & $51(17.6)$ \\
\hline & Women & 226 (77.9) & & Associate's & 54 (18.6) \\
\hline & & 112 (38.6) & & Bachelor's & 162 (55.9) \\
\hline \multirow{3}{*}{ Age } & 31 - 40 years & 131 (14.5) & & MS-up & $23(7.9)$ \\
\hline & 41 - 50 years & 42 (14.5) & & 1 to 10 years & $166(57.2)$ \\
\hline & Up to 50 years & $5(1.7)$ & Work & 11 - 20 years & 93 (32.1) \\
\hline \multirow{2}{*}{$\begin{array}{l}\text { Marital } \\
\text { status }\end{array}$} & Single & $67(23.1)$ & experience & \multirow{2}{*}{21 - 30 years } & \multirow{2}{*}{31 (10.7) } \\
\hline & Married & 223 (76.9) & & & \\
\hline
\end{tabular}
ownership types of governmental, private and Social Security. The major part of organizational learning capability is related to governmental hospitals $(10.31 \pm 53.06)$ while private hospitals with an average of $38.9 \pm 47.38$

Table 1. Demographic specifications of staff in the studied hospitals—2014. 
had the lowest rating and finally, the Social Security hospitals obtained the average learning capability of 10.27 \pm 50.74 .

The Mann-Whitney U-test results presented in Table 3 showed that there was a significant relationship between marital status and the type of hospital in terms of public and specialized being and the organizational learning, however, no such a relationship existed between gender and organizational learning.

In Table 4 the results of the Kruskal-Wallis test are provided to examine the relationship between variables (age, education, work experience, employment status, job category and type of hospital ownership) and the organizational learning capability. The results showed that there is no significant relationship between the age and organizational learning capability $(\mathrm{p}=0.76)$ and no significant relationship was observed between the level of education and organizational learning capability $(\mathrm{p}=0.781)$.

As is evident from the above table, there is no relationship between work experience and organizational learning capability $(\mathrm{p}=0.544)$. This relationship was significant for the employment status variable and the organizational learning capability $(\mathrm{p}=0.034)$. Finally, there was a significant difference between the average of organizational learning capability and the type of job category $(p=0.043)$ and hospital ownership $(p=0.02)$.

\section{Discussion}

The study showed that the mean score of organizational learning capability in hospitals in Bandar Abbas City for public, social security and privacy hospitals were $10.31 \pm 53.06,10.270 \pm 50.74$ and $9.38 \pm 47.38$, respectively which indicates the average-up rating of the hospitals in the city from the perspective of the learning environment and also indicates the need of these hospitals to be as learners. This value was 52.58 percent in Yaghubi and colleagues [16] in Children's Hospital Medical Center and was obtained 38.2 percent for another study by Yaghubi and colleagues [17] in Isfahan that these numbers are different according to their different research community and the different conditions.

Table 2. The organizational learning capability in hospitals of Bandar Abbas City according to the type of ownership—2014.

\begin{tabular}{ccccc}
\hline Ownership type & Mean & Std. deviation & Maximum & Minimum \\
\hline Governmental & 53.06 & 10.31 & 85 & 26 \\
Private & 47.38 & 9.68 & 73 & 24 \\
Social Security & 50.74 & 10.27 & 75 & 26 \\
\hline
\end{tabular}

Table 3. The relationship between organizational learning and gender, marital status and type of hospital activity—2014.

\begin{tabular}{ccc}
\hline Variables & $\mathrm{Z}$ & P-value \\
\hline Gender & -1.217 & 0.224 \\
Marital status & -2.177 & 0.029 \\
Type of hospital & -1.872 & 0.049 \\
\hline
\end{tabular}

Table 4. The relationship between demographic variables and hospital ownership with organizational learning capability2014.

\begin{tabular}{|c|c|c|c|}
\hline Variables & Chi-square & df & P-value \\
\hline Age & 1.171 & 3 & 0.76 \\
\hline Education level & 1.082 & 3 & 0.781 \\
\hline Work experience & 1.219 & 2 & 0.544 \\
\hline Employment status & 8.65 & 2 & 0.034 \\
\hline Job category & 5.535 & 2 & 0.043 \\
\hline Type of hospital ownership & 12.859 & 2 & 0.02 \\
\hline
\end{tabular}


In general, among the studied hospitals in three ownership kinds of governmental, private and social security, the most organizational learning was obtained for public hospitals $(10.31 \pm 53.06)$ while the private hospitals with an average of $9.38 \pm 47.38$ had the lowest rate and finally, the Social Security hospitals obtained the mean learning capability of $10.27 \pm 50.74$. While in a study by Aghdasi and Khakzar Befruii [18] and a study by Abbasi Moghadam et al. [19] the level of organizational learning capability in private hospitals was more than governmental hospitals.

In the research hypotheses section, the Mann-Whitney U-test results revealed that among the dimensions of organizational learning capability, the systemic vision has a significant correlation with gender $(p=0.04)$ and three dimensions of management commitment, outdoor space and experimentation and transferring and integration did not have relationship with gender. This is vice versa to the study by Yaghubi and colleagues [16] that a significant relationship was found between gender and outdoor space and experimentation and transferring and integration of knowledge dimensions (respectively: $p=0.048$ and $p=0.001$ ) and no significant correlation was found between the management commitment and the systemic vision.

In a study by Bahadori and colleagues [20] there was no significant association between any of the dimensions and gender and also in Abbasi Moghadam et al. [21] there was a relationship only between the outdoor and experimentation with gender $(\mathrm{p}=0.005)$. Also, in a study by Heidari et al. [15] a significant relationship was found between the management commitment $(p=0.003)$ and the transferring and integration of knowledge ( $p=0.007)$ and in total, in this study, no significant correlation was found between the organizational learning capability and gender ( $\mathrm{p}=0.224)$. In two studies, Yaghubi and colleagues [16] and Haideri and colleagues [15], there was relationship between gender and organizational learning capability $(p=0.004)$ and in this aspect, they are different with this study.

In this study, a significant relationship was found between the marital status and the systemic vision (0.030) while in Bahadori's study, no significant relationship was observed between any of the dimensions of organizational learning and marital status [20]. The type of hospital activity is one of the most important variables in determining the level of the organizational learning. In the present study, it was shown that the type of hospital activity is related to the systemic vision ( $p=0.015)$, but such a relationship wasn't observed for the other dimensions. In total, there was a significant relationship between the marital status $(p=0.029)$ and the type of hospital activity ( $p=0.049$ ) with the organizational learning capability.

The second part of the test results was related to the Kruskal-Wallis test. In this section, the results went in a way that no significant relationship was found between age and education level with organizational learning capability and its dimensions. The results have also been confirmed in the studies by Yaghubi and colleagues [16] [17] and Bahadori and colleagues [20]. In Bahadori's study [20] no significant relationship was found between employment status and work experience with the dimensions of organizational learning capability. Yaghubi and colleagues [16] also didn't find any relationship between work experience and the dimensions of organizational learning. In the first study of Abbasi Moghadam et al. [21] a significant relationship was found between the systemic vision $(p=0.015)$ and the employment status variable. Almost similar results were obtained in the present study so that no significant relationship was found between employment status and work experience with all dimensions of organizational learning capability.

So generally, a significant relationship was found between employment status and organizational learning capabilities $(p=0.034)$ that this relation was confirmed in a study of Yaghubi and colleagues $(p=0.003)$, but no significant relationship was found with work experience which is similar to the study of Yaghubi and colleagues. In this study, a significant relationship was observed between the job category and the systemic vision $(p=0.03)$ and no relation was found with other three dimensions. In general, there was a significant correlation between the job category and organizational learning capability $(\mathrm{p}=0.043)$ which was consistent with Yaghubi and colleagues $(p=0.002)$. Finally, the relationship between hospital ownership and dimensions of organizational learning showed that there was a significant relation between the dimensions of management commitment $(p=0.05)$, the systemic vision $(p=0.046)$ and outdoor space and experimentation $(p=0.000)$ with the type of hospital ownership, but no significant relationship was found between the dimension of transferring and integration of knowledge.

\section{Conclusions}

Health care systems and organizations affiliated to health systems are among the organizations that are of utmost importance and sensitivity due to the variety of activities and providing health care, education and research ser- 
vices for the bulk of the population and playing a pivotal role in maintaining and improving health. On the other hand, followed by understanding the importance of health subject as the main axis of sustainable development, all relevant organizations should target learning on their agenda.

Based on the findings and the above discussion, it can be concluded that with an increase in staff learning, their performance will be improved and so patient satisfaction will be promote. These findings of this study can be interpreted in a way that in a team, all individuals share their knowledge and experience to each other and use each other's experiences and skills to improve their skills and learning and a comprehensive organizational learning improvement which is obtained by being in a team, and in turn, leads to learn the needed principles and requirements for the optimal performance and ultimately improves the performance of employees at all levels and processes of the organization.

Today, organizations need effective and efficient staff in order to achieve their objectives for growth and comprehensive development and in general, the efficiency and effectiveness of organizations depend on the efficiency and effectiveness of human resources and personnel in the organization that the creation of knowledge and learning is of the most important factors affecting the performance of employees, hence, it is needed to seek effective methods to enhance this component that one of them is moving toward learner organizations. On the other hand, the current accelerated developments caused that organizations have been faced with many challenges. Thus, in order to cope with these challenges, learning should be an integral part of their life and daily work. Although in recent years, considerable progresses have been emerged in the fields of biology and medical sciences in Iran and other countries which were the results of research and studies, however, in our country, no comprehensive studies have not been done on the application of the learner organization model. Hence, the need for studies and research to design and application of this model is recommended in the health care system as one of the newest and most effective theories and management approaches.

\section{Acknowledgements}

We are grateful for the participation of the staff hospitals in Bandar Abbas City. in this study. This study was supported by Tehran University of Medical Sciences.

\section{Competing Interests}

The authors declare that they have no competing interests.

\section{Authors' Contributions}

F.F. was the principal investigator and wrote the paper. A.I. was also the principal author of this paper. She managed the study throughout the work. She contributed equally to this work with F.F. A.R.F. has made substantial contributions to the analysis and interpretation of the data. F.F. and A.I. also reviewed the first draft and wrote the final version of the manuscript. All authors read and approved the final manuscript.

\section{References}

[1] Hult, G.T.M., Hurley, R.F. and Knight, G.A. (2004) Innovativeness: Its Antecedents and Impact on Business Performance. Industrial Marketing Management, 33, 429-438. http://dx.doi.org/10.1016/j.indmarman.2003.08.015

[2] Jerez-Gómez, P., Céspedes-Lorente, J. and Valle-Cabrera, R. (2005) Organizational Learning and Compensation Strategies: Evidence from the Spanish Chemical Industry. Human Resource Management, 44, 279-299. http://dx.doi.org/10.1002/hrm.20071

[3] Lynn, G.S. and Akgun, A.E. (2000) A New Product Development Learning Model: Antecedents and Consequences of Declarative and Procedural Knowledge. International Journal of Technology Management, 20, 490-510. http://dx.doi.org/10.1504/IJTM.2000.002889

[4] Jerez-Gomez, P., Céspedes-Lorente, J. and Valle-Cabrera, R. (2005) Organizational Learning Capability: A Proposal of Measurement. Journal of Business Research, 58, 715-725. http://dx.doi.org/10.1016/j.jbusres.2003.11.002

[5] Fang, C.-H., Chang, S.-T. and Chen, G.-L. (2011) Organizational Learning Capability and Organizational Innovation: The Moderating Role of Knowledge Inertia. African Journal of Business Management, 5, 1864-1870.

[6] Goh, S. and Richards, G. (1997) Benchmarking the Learning Capability of Organizations. European Management Journal, 15, 575-583. http://dx.doi.org/10.1016/S0263-2373(97)00036-4 
[7] Yeung, A.K., Ulrich, D.O., Nason, S.W. and Von Glinow, M.A. (1999) Organizational Learning Capability. Oxford University Press, New York.

[8] Chiva, R. and Alegre, J. (2009) Organizational Learning Capability and Job Satisfaction: An Empirical Assessment in the Ceramic Tile Industry. British Journal of Management, 20, 323-340. http://dx.doi.org/10.1111/j.1467-8551.2008.00586.x

[9] Alegre, J. and Chiva, R. (2008) Assessing the Impact of Organizational Learning Capability on Product Innovation Performance: An Empirical Test. Technovation, 28, 315-326. http://dx.doi.org/10.1016/j.technovation.2007.09.003

[10] Rashidi, M.M.H.M. and Jafari Farsani, J. (2010) The Relationship between Intellectual Assets Organizational Learning Capability at the Institute for International Energy Studies. Management and Human Resources in the Oil Industry, 11, 59-76.

[11] Ulrich, D., Jick, T. and Glinow, M.A.V. (1993) High-Impact Learning: Building and Diffusing Learning Capability. Organizational Dynamics, 22, 52-66. http://dx.doi.org/10.1016/0090-2616(93)90053-4

[12] Chaston, I., Badger, B., Mangles, T. and Sadler-Smith, E. (2001) Organisational Learning Style, Competencies and Learning Systems in Small, UK Manufacturing Firms. International Journal of Operations \& Production Management, 21, 1417-1432. http://dx.doi.org/10.1108/EUM0000000006224

[13] Tsai, Y. (2014) Learning Organizations, Internal Marketing, and Organizational Commitment in Hospitals. BMC Health Services Research, 14, 152. http://dx.doi.org/10.1186/1472-6963-14-152

[14] Aghdasi, M. and Khakzar Bafruei, M. (2009) Measuring Level of Organizational Learning Capabilities in Hospitals. International Journal of Industrial Engineering \& Production Management, 19, 71-83.

[15] Heidari, S., Sadeghi, T., Vanaki, Z., Khosroangam, M. and Rodini, A. (2014) Organizational Learning Capabilities of Nurses. Journal of Nursing Management, 2, 56-63.

[16] Yaghoubi, M., Agharahimi, Z., Daryabeygi, M. and Javadi, M. (2012) The Relationship between Application of Organizational Learning and Demographic Features of Staffs Working in Pediatrics Medical Center. Iranian Journal of Medical Education, 11, 1074-1082.

[17] Yaghoubi, M., Karimi, S., Javadi, M. and Nikbakht, A. (2011) A Correlation Study on Organization Learning and Knowledge Management in Staffs in Selected Hospitals of Isfahan University of Medical Sciences. Journal of Health Administration, 13, 65-75.

[18] Aghdasi, M. and Khakzar Befruei, M. (2009) Comparative Study of Organizational Learning Capabilities as an Organizational Source of Knowledge in Public and Private Hospitals of Tehran: Nurses Perspectives. Iran Journal of Nursing, 21, 69-79.

[19] Abbasi, H., Eydi, H. and Karami Matin, B. (2014) Comparison of Organizational Learning Capabilities of the Personnel in Public and Private Sector Hospitals of Kermanshah. Journal of Kermanshah University of Medical Sciences, 17, 797-803.

[20] Bahadori, M., Hamouzadeh, P., Qodoosinejad, J. and Yousefvand, M. (2010) Organizational Learning Capabilities of Nurses in Iran. International Journal of Global Business and Management Research, 4, 248-254.

[21] Abbasi Moghadam, M.A., Bakhtiari, M., Raadabadi, M. and Bahadori, M. (2013) Organizational Learning and Empowerment of Nursing Status; Tehran University of Medical Sciences. Education Strategies in Medical Sciences, 6 , 113-118.

\section{Abbreviations}

OLC: Organizational Learning Capabilities 


\section{Appendix}

Games questioner

Explanation of organizational learning capability variants at concerned hospitals

\begin{tabular}{|c|c|}
\hline Capability & Index \\
\hline \multirow{5}{*}{$\begin{array}{c}\text { Managerial } \\
\text { Commitment }\end{array}$} & Frequently involvement of personnel in decision making processes \\
\hline & Pay attention to personnel learning as an investment \\
\hline & Benefiting from new job methods by managers \\
\hline & Pay attention to personnel learning capability as a key factor \\
\hline & Encouraging of innovative ideas at work place \\
\hline \multirow{3}{*}{$\begin{array}{c}\text { Systems } \\
\text { Perspective }\end{array}$} & Having general knowledge about job objectives \\
\hline & Knowledge of personnel about participation for achieving to the overall objective \\
\hline & Coordinated relation of all sectors with each other \\
\hline \multirow{4}{*}{$\begin{array}{c}\text { Openness \& } \\
\text { Experimentation }\end{array}$} & Welcoming to new methods for improvement of work performance \\
\hline & Benefiting from previous methods and techniques doing by other hospitals \\
\hline & Benefiting from relevant experiences \& ideas provided by external sources as useful tools \\
\hline & Insisting of personnel on their own ideas and make suggestion regarding to their own work performance method \\
\hline \multirow{4}{*}{$\begin{array}{l}\text { Knowledge } \\
\text { Transfer } \\
\text { \& Integration }\end{array}$} & Analysis and finding of errors \& failures at all levels \\
\hline & Talking and discussing about new ideas, programs and useful activities for work performance \\
\hline & Having different tools and instruments like accidents registration books for maintenance of previous experiences \\
\hline & Problem solving through previous registered experiences \\
\hline
\end{tabular}

